\title{
Genetic Polymorphisms of ABCB1 Gene in Patients Having Resistance to Clopidogrel
}

\author{
R. Madhavi1, D. Rajasekhar'1, P. V. G. K. Sarma², V. Vanajakshamma1, G. Sowjenya ${ }^{1}$, \\ K. Sreedhar1, C. Kapil1 \\ ${ }^{1}$ Department of Cardiology, Sri Venkateswara Institute of Medical Sciences, Tirupati, India \\ ${ }^{2}$ Department of Biotechnology, Sri Venkateswara Institute of medical Sciences, Tirupati, India \\ Email: drmadhavi_222@yahoo.co.in
}

How to cite this paper: Madhavi, R., Rajasekhar, D., Sarma, P.V.G.K., Vanajakshamma, V., Sowjenya, G., Sreedhar, K. and Kapil, C. (2017) Genetic Polymorphisms of ABCB1 Gene in Patients Having Resistance to Clopidogrel. World Journal of Cardiovascular Diseases, 7, 390-398.

https://doi.org/10.4236/wjcd.2017.711037

Received: August 7, 2017

Accepted: November 12, 2017

Published: November 15, 2017

Copyright $\odot 2017$ by authors and Scientific Research Publishing Inc. This work is licensed under the Creative Commons Attribution International License (CC BY 4.0).

http://creativecommons.org/licenses/by/4.0/

\begin{abstract}
Objectives: We sought to study the genetic polymorphisms of $A B C B 1$ gene in post percutaneous coronary intervention (PCI) patients with clopidogrel resistance. Background: Dual antiplatelet therapy (DAPT) is a guideline mandated therapy for patients who undergo PCI. However there exists interindividual variability in drug response to the antiplatelet agents leading to recurrent thrombotic events. Genetic polymorphisms of $\mathrm{ABCB} 1$ gene are one among the causes of this interindividual variability. Methods: It is a single center prospective trial and includes 221 patients who underwent PCI and were given clopidogrel as a part of DAPT. Platelet reactivity was assessed by grading of platelet activity index (PAI) and considered as high on treatment platelet reactivity (HTPR), i.e., clopidogrel resistance if PAI $>5$. Genetic analysis for $\mathrm{ABCB} 1 \mathrm{C}-\mathrm{T}$ polymorphism was done by polymerase chain reaction (PCR) and single strand confirmation polymorphism (SSCP) analysis. Results: Amongst 221 patients, 37 (16.7\%) patients had ABCB1 C-T polymorphisms. The mean PAI value in these patients was $5.1 \pm 3.0$, while it was $3.5 \pm$ 2.5 in those patients without ABCB1 C-T polymorphisms $(p=0.004)$. Compared to patients without HTPR, the occurrence of primary endpoints was not significantly increased in patients with HTPR except for stent thrombosis which was significantly high in patients with HTPR. HTPR was also associated with ABCB1 C-T polymorphisms $(p=0.04)$, but these polymorphisms did not predict the clinical outcome. Conclusions: There was significant prevalence of $\mathrm{ABCB} 1 \mathrm{C}-\mathrm{T}$ polymorphisms in patients with HTPR. However it was not an independent risk factor for clopidogrel resistance and also it did not influence adverse cardiovascular outcomes.
\end{abstract}

\section{Keywords}

ABCB1, Percutaneous Coronary Intervention, Clopidogrel Resistance, Cardiology 


\section{Introduction}

A 4-fold rise in the prevalence of coronary heart disease (CHD) is seen in India during the past 40 years and the current prevalence is estimated to be between $7 \%$ and $13 \%$ in urban [1] [2] [3] and between $2 \%$ and $7 \%$ in rural [4] [5] populations. Coronary artery disease (CAD) is characterized by atherosclerosis in the epicardial coronary arteries. Dramatic expansion in the use of PCI is seen in the past three decades and PCI has evolved from plain old balloon angioplasty (POBA) to implantation of bare metal stent (BMS) to drug eluting stent (DES) and currently to the use of biovascular scaffolds.

Antiplatelet drugs are the cornerstone in the management of atherothrombotic vessel occlusions. Clopidogrel, as a part of dual antiplatelet therapy (DAPT), has substantially reduced both the incidence and mortality of acute coronary syndromes (ACS) and has improved the efficacy of percutaneous coronary intervention (PCI) [6].

It is recommended that patients with bare metal stent (BMS) and drug eluting stent (DES) should receive DAPT for 3 and 12 months respectively. Despite this guide line directed regimen stent thrombosis (ST) remained a significant complication resulting in recurrent ischemic events. This ST may be attributed to many factors and drug nonresponsiveness also contributes to it. Besides medication, non compliance (pseudo resistance), pharmacodynamic and pharmacokinetic mechanisms are involved in variability in responsiveness to antiplatelet agents, and these include drug bioavailability, drug-drug interactions, cytochrome P-450 (CYP 450) activity and genetic polymorphisms (like ABCB1 C-T polymorphisms). Numerous observational studies have consistently shown an association between antiplatelet drug nonresponsiveness and adverse clinical outcomes. Association of CYP 450 gene polymorphisms with clopidogrel resistance was proven in many trials. The ABCB1 gene encodes multi drug resistance protein 1 (MDR1), which is an ATP dependent efflux transporter, thus responsible for the transport of a portion of drug (clopidogrel) back into the lumen thereby reducing the bioavailability. However, influence of $\mathrm{ABCB} 1 \mathrm{C}-\mathrm{T}$ genetic polymorphisms on clopidogrel nonresponsiveness is still controversial.

\section{Materials and Methods}

This study was approved by our institutional ethics committee. Study was conducted after obtaining written informed consent from all participants. Study group consisted of 221 patients with CAD including both ACS and stable ischemic heart disease (SIHD) of either sex and age more than 18 years and had undergone PCI. Patients were diagnosed and underwent procedures in the department of Cardiology, Sri Venkateswara institute of medical sciences, Tirupati, India. Patients using drugs affecting the metabolism of clopidogrel (phenytoin, proguanil, diazepam and some antidepressants), with renal failure, cirrhosis or with any chronic inflammatory disease, allergic to thienopyridines, with platelet count less than $1 \mathrm{lakh} / \mathrm{cu} \cdot \mathrm{mm}$ or more than $5 \mathrm{lakh} / \mathrm{cu} \cdot \mathrm{mm}$., with anemia (hema- 
tocrit less than $30 \%$ ) or with polycythemia (hematocrit more than 52\%), with active bleeding (excluding menstruation) or significant gastrointestinal bleeding within the previous 6 months, those with history of hemorrhagic stroke or subarachnoid hemorrhage, who underwent major surgical procedure within 2 weeks before enrollment, patients who were unwilling to participate in the study and pregnant women were excluded from the study.

Patients were treated with DAPT with loading doses of both aspirin and clopidogrel followed by maintenance dose.

A detailed demographic, historical, clinical, biochemical and haematological data was collected.

Two millilitres (ml) citrated whole blood (WB) sample for platelet aggregation testing was obtained on day 2 after maintenance dose of DAPT following PCI. If the patients were on GPIIb/IIIa inhibitors sample was collected 2 days after tirofiban infusion and after 2 weeks in case of abciximab. Whole blood mixed with EDTA $(3 \mathrm{ml})$ was collected for genetic analysis.

Platelet function:

Assessment of platelet function/aggregation was done, using Aggre Guide A100 aggregometer. It is a point of care test (POCT), which is based on the principle of light scattering technique. With this, the more active the platelets the more aggregates are formed and higher the PAI (PAI > 5). Conversely, if the platelets are inhibited by antiplatelet drugs, they are not activated by adenosine diphosphate (ADP) to form aggregates and the Aggre Guide shows a low PAI $(\mathrm{PAI} \leq 5)$, thus Aggre Guide's PAI is a function of the number of aggregates.

Genetic analysis:

Salting out procedure was carried out for extraction of DNA from human blood. Isolated DNA was analyzed through agarose gel electrophoresis. Primers of the ATP-binding cassette, sub family B, member 1 (ABCB1) were designed from the nucleotide gene sequence present in the data base (http://www.ncbi.nlm.nih.gov) by using the internet available free software's; Oligo 6, NCBI blast and primer 3. The accession number of the gene is NM_000927.4. The primers were synthesized at Eurofins Genomics Pvt Ltd., Bangalore, India. The chromosomal DNA isolated from blood was used as a template for the amplification of ABCB1 gene using PCR. The forward

5'-AGCCCATCCTGTTTGACTGC 3'and reverse

5'-TGTATGTTGGCCTCCTTTGC-3'primers of ABCB1 gene were used. Amplified gene was subjected to SSCP analysis.

End points:

In hospital and 6 month clinical events were collected for all patients and recorded. The primary end points of the study were stent thrombosis, myocardial infarction and death. Secondary end points included in hospital major bleeding and other bleeding manifestations during the maintenance phase. These end points were studied in patients with $\mathrm{ABCB} 1 \mathrm{C}-\mathrm{T}$ polymorphisms and those without these polymorphisms. 
Statistical analysis:

Data was collected on predesigned Microsoft Excel spread sheets and the entries were double checked for any data entry errors. Continuous data was presented as mean and standard deviation; categorical variables were presented as counts with percentages. Differences observed if any were tested for significance with independent student's t-test for continuous data and Fischer's exact test or Chi-square test as appropriate for categorical data.

All the statistical analysis was performed with SPSS version 20.0 (IBM Corp., Armonk, NY: USA). A $p$-value $<0.05$ was considered as significant.

\section{Results}

The demographic and historical characteristics are shown in Table 1. The mean age in the study group was $55.7 \pm 9.9$ years. Platelet aggregation inhibition testing was done and grading of PAI was done. Mean PAI was significantly high in females $(4.1 \pm 2.4)$ compared to males $(2.5 \pm 2.4)$ with $p<0.001$.

Patients were classified as those having PAI $>5$ (HTPR) and PAI $<5$. The mean age, mean BMI and mean of various haematological and biochemical parameters in patients with $\mathrm{PAI} \leq 5$ and PAI $>5$ are given Table 2. Patients with PAI $>5$ had statistically significant higher age (mean $58.7 \pm 8.7$ years) compared to patients with PAI $\leq 5$ (mean age $56.2 \pm 9.9$ years) $(p=0.003)$.

Smokers had low on-treatment platelet reactivity compared to non-smokers $3.1 \pm 2.3$ and $3.8 \pm 2.7$ respectively $(p=0.041)$.

Genetic analysis for ABCB1 C-T polymorphisms (Figure 1 and Figure 2) was done in all patients and correlated with the PAI. Of the 221 patients, 37 (16.9\%) patients had ABCB1 C-T polymorphisms. The mean PAI in patients with ABCB1 C-T polymorphisms was high $(5.1 \pm 3.0)$ when compared to those without ABCB1 C-T polymorphisms (3.4 \pm 2.5$)$ with $p=0.004$ (Table 3 ). The mean

Table 1. Baseline variables in study population.

\begin{tabular}{cc}
\hline Variable & \\
\hline Age $($ years $)$ & $56.8 \pm 9.8$ \\
BMI $\left(\mathbf{k g} / \mathrm{m}^{2}\right)$ & $22.6 \pm 3.9$ \\
Hemoglobin $(\mathrm{gm} / \mathrm{dl})$ & $13.2 \pm 2.1$ \\
Platelet count $\left(\mathrm{lakhs} / \mathrm{mm}^{3}\right)$ & $2.7 \pm 0.8$ \\
Serum Urea $(\mathrm{mg} / \mathrm{dl})$ & $28.7 \pm 10.4$ \\
Serum Creatinine $(\mathrm{mg} / \mathrm{dl})$ & $1.0 \pm 0.3$ \\
Total cholesterol $(\mathrm{mg} / \mathrm{dl})$ & $180.6 \pm 49.8$ \\
HDL $(\mathrm{mg} / \mathrm{dl})$ & $35.6 \pm 6.76$ \\
LDL $(\mathrm{mg} / \mathrm{dl})$ & $113.2 \pm 41.0$ \\
Triglycerides $(\mathrm{mg} / \mathrm{dl})$ & $146.8 \pm 96.8$
\end{tabular}

BMI: Body mass index; SBP: Systolic blood pressure; DBP: Diastolic blood pressure; HDL: High density lipoprotein; LDL: Low density lipoprotein; PAI: platelet activity index. 


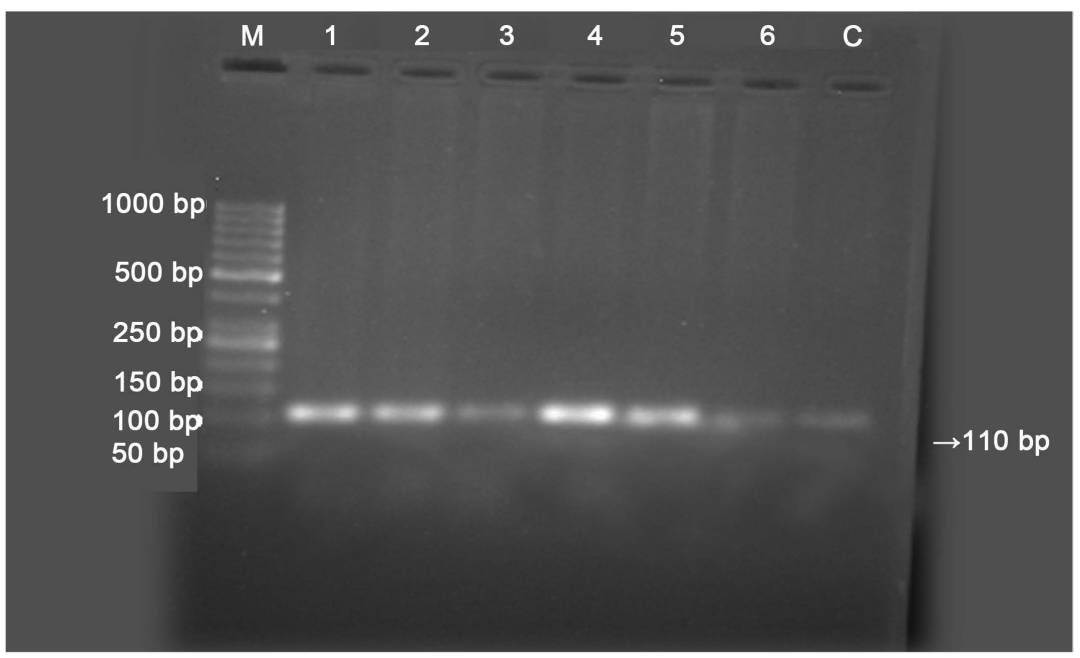

$\mathrm{M}=$ Markers: 50 base pairs ladder, 1 - 6 = Patients' sample showing $\mathrm{ABCB} 1$ gene, $\mathrm{C}=\mathrm{Control}$

Figure 1. Agarose gel electrophoresis of $\mathrm{ABCB} 1$ gene.

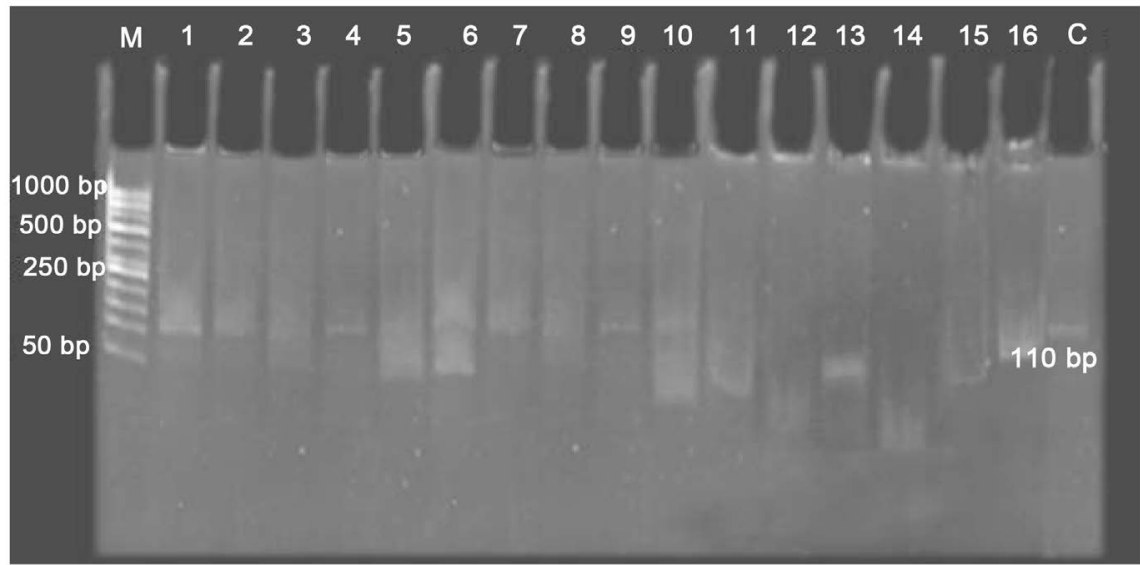

$\mathrm{M}=$ Markers: 50 base pairs ladder, $1-16=$ Patients, $\mathrm{C}=$ Control

Figure 2. SSCP gel (6\%) showing difference in mobility of ABCB1 gene in few patients.

Table 2. Effect of demographic and hematologic parameters on platelet reactivity.

\begin{tabular}{cccc}
\hline Variable & PAI $<5$ & PAI $>\mathbf{5}$ & $p$ value \\
\hline Age (years) & $56.2 \pm 9.9$ & $58.7 \pm 8.7$ & 0.003 \\
BMI $\left(\mathrm{kg} / \mathrm{m}^{2}\right)$ & $22.7 \pm 3.9$ & $22.4 \pm 4.5$ & 0.672 \\
Hemoglobin $(\mathrm{gm} / \mathrm{dl})$ & $13.46 \pm 2.10$ & $12.29 \pm 1.79$ & 0.000 \\
Platelet count $\left(\mathrm{lakhs} / \mathrm{mm}^{3}\right)$ & $2.63 \pm 0.80$ & $3.03 \pm 0.8$ & 0.002 \\
Serum Urea (mg/dl) & $28.8 \pm 10.6$ & $28.6 \pm 9.4$ & 0.922 \\
Serum Creatinine (mg/dl) & $1.0 \pm 0.3$ & $0.9 \pm 0.3$ & 0.566 \\
Total cholesterol (mg/dl) & $180.6 \pm 49.8$ & $177.4 \pm 42.9$ & 0.709 \\
HDL (mg/dl) & $35.5 \pm 6.7$ & $35.8 \pm 6.2$ & 0.808 \\
LDL (mg/dl) & $113.3 \pm 41.0$ & $113.1 \pm 37.3$ & 0.974 \\
Triglycerides (mg/dl) & $147.4 \pm 96.8$ & $147.6 \pm 53.2$ & 0.858 \\
\hline
\end{tabular}

BMI: Body mass index; SBP: Systolic blood pressure; DBP: Diastolic blood pressure; HDL: High density lipoprotein; LDL: Low density lipoprotein; PAI: platelet activity index. 
Table 3. Correlation of ABCB1 C-T polymorphisms with PAI.

\begin{tabular}{cccc}
\hline & $\begin{array}{c}\text { Number of patients with } \\
\text { ABCB1 C-T polymorphisms }\end{array}$ & $\begin{array}{c}\text { Number of patients without } \\
\text { ABCB1 C-T polymorphisms }\end{array}$ & $p$ value \\
\hline $\begin{array}{c}\text { Number of patients } \\
\text { Mean PAI }\end{array}$ & $37(16.9 \%)$ & $184(83.1 \%)$ & 0.004 \\
\hline
\end{tabular}

PAI: Platelet activity index; ABCB1: ATP-binding cassette transporter, sub-family B, member 1 .

age in patients with $\mathrm{ABCB} 1 \mathrm{C}-\mathrm{T}$ polymorphisms was $58.6 \pm 8.5$, while it was 56.9 \pm 9.1 in patients without $\mathrm{ABCB} 1$ Polymorphisms which was not statistically significant $(p=0.44)$. Amongst 37 patients with ABCB1 C-T polymorphisms 20 (54.1\%) were female and 17 (45.9\%) were males. Females had a significantly higher incidence of ABCB1 C-T polymorphisms $(p<0.01)$. Also females were having high PAI compared to males $4.1 \pm 2.4$ and $2.5 \pm 2.4$ respectively ( $p<$ 0.001).

The outcomes in patients with PAI $\leq 5$ and PAI $>5$ are shown in Table 4. Patients with HTPR as evidenced by high PAI had significant ST compared to those with $\mathrm{PAI} \leq 5$. We found that amongst 37 patients who had polymorphisms of $A B C B 12$ patients had stent thrombosis while stent thrombosis occurred in 3 patients who did not have ABCB1 polymorphisms $(n=184)$. However this was not statistically significant difference $(p=0.17)$.

\section{Discussion}

As a part of DAPT, clopidogrel being low in cost and effective is one of the most commonly prescribed antiplatelet medications to prevent recurrent events after ACS and in those who under PCI. Platelet aggregation inhibition in response to antiplatelet drugs varies widely. In this study we found that $15.8 \%$ of patients on antiplatelet therapy were having $\operatorname{HTPR}(p<0.001)$, consistent with the prevalence of clopidogrel nonresponse of about $4 \%-30 \%$ in previous studies [7]-[12]. The reported rates varied between studies because of the technique used to measure the extent of platelet aggregation and the presence of factors contributing to greater platelet reactivity.

In consistence with the SENIOR PLATELET trial [13], our study showed strong positive correlation with age i.e., increasing platelet reactivity with age. In contrary to our study and SENIOR PLATELET trial (who assessed patients with loading dose of clopidogrel prior to angioplasty), the age of presentation did not differ with the presence or absence of $\mathrm{ABCB} 1$ genetic polymorphisms.

Consistent with the study of Bliden et al. [14], our study showed a significant negative correlation with smoking i.e., smokers had low residual platelet reactivity. Cigarette smoking is an inducer of CYP1A2 that can increase the active concentration of active metabolite.

Consistent with findings of $\mathrm{N} \mathrm{J}$ Breet et al. [15], our study showed that females had a significant higher PAI compared to males. Also there was significant high prevalence of $\mathrm{ABCB} 1$ polymorphisms in females. 
Table 4. Incidence of stent thrombosis in clopidogrel patients.

\begin{tabular}{cccc}
\hline & PAI $\leq \mathbf{5}$ & PAI $>\mathbf{5}$ & $p$ value \\
\hline Number of patients & 170 & 51 & 0.01 \\
Number of stent thrombosis & $1(0.5 \%)$ & $4(7.8 \%)$ & \\
\hline
\end{tabular}

In our study we found polymorphisms of $\mathrm{ABCB} 1$ gene in $16.9 \%$. This protein is responsible for the bioavailability of clopidogrel in the intestine and an influence of a single nucleotide polymorphisms (SNP) within the ABCB1 gene (C3435T) was first described by Taubert et al. in 2006 [16]. Our findings were similar to one study in which the ABCB1 C3435T polymorphism influenced $\mathrm{ADP}$ dependent platelet reactivity and showed that $\mathrm{T}$-allele carriers were likely to have a poor response to antiplatelet therapy in the lab test [17]. In contrary to the findings of Mega et al. [18], Su et al. [19], and Simon et al. [20], who showed an association of $\mathrm{ABCB} 1$ polymorphisms with adverse cardiovascular outcomes in the setting of treatment with clopidogrel, our study did not show any significant effect on cardiovascular outcomes.

Limitations:

- Sample size in our study was small because of which we did not get significant differences in outcomes.

- It was a single centre study, and hence the results cannot be generalized to the total population.

- No single platelet function testing available as on today is a standardized method.

- Genetic testing is technically demanding, time consuming, expensive and generally not reimbursable. Also there is limited availability of point-of-care genetic assay.

\section{Conclusion}

Resistance to oral antiplatelet therapy is common. There is significant prevalence of ABCB1 C-T polymorphisms in patients with HTPR. However, it was not an independent risk factor for clopidogrel resistance and also it did not influence adverse cardiovascular outcomes.

\section{References}

[1] Mohan, V., Deepa, R., Rani, S.S., et al. (2001) Prevalence of Coronary Artery Disease and Its Relationship to Lipids in a Selected Population in South India. Journal of the American College of Cardiology, 38, 682-687. https://doi.org/10.1016/S0735-1097(01)01415-2

[2] Gupta, R., Gupta, V.P., Sarna, M., et al. (2002) Prevalence of Coronary Heart Disease and Risk Factors in an Urban Indian Population: Jaipur Heart Watch-2. Indian Heart Journal, 54, 59-66.

[3] Kamili, M.A., Dar, I.H., Ali, G., et al. (2007) Prevalence of Coronary Heart Disease in Kashmiris. Indian Heart Journal, 61, 44-49.

[4] Gupta, A.K., Bharadwaj, A., Ashotra, S., et al. (2002) Feasibility and Training of 
Multipurpose Workers in Detection, Prevention and Control of Coronary Artery Disease in Apple-Belt of Shimla Hills. South Asian Journal of Preventive Cardiology, 6, 17-22.

[5] Kumar, R., Singh, M.C., Ahlawat, S.K., et al. (2006) Urbanization and Coronary Heart Disease: A Study of Urban-Rural Differences in Northern India. Indian Heart Journal, 58, 126-130.

[6] Silber, S., Albertsson, P., Aviles, F., et al. (2005) Guidelines for Percutaneous Coronary Interventions. The Task Force for Percutaneous Coronary Interventions of the European Society of Cardiology. European Heart Journal, 26, 804-847. https://doi.org/10.1093/eurheartj/ehi138

[7] Jaremo, P., Lindahl, T.L., Fransson, S.G. and Richter, A. (2002) Individual Variations of Platelet Inhibition after Loading Doses of Clopidogrel. Journal of Internal Medicine, 252, 233-238. https://doi.org/10.1046/j.1365-2796.2002.01027.x

[8] Gurbel, P.A., Bliden, K.P., Hiatt, B.L. and O’Connor, C.M. (2003) Clopidogrel for Coronary Stenting: Response Variability, Drug Resistance, and the Effect of Pretreatment Platelet Reactivity. Circulation, 107, 2908-2913. https://doi.org/10.1161/01.CIR.0000072771.11429.83

[9] Muller, I., Besta, F., Schulz, C., Massberg, S., Schonig, A. and Gawaz, M. (2003) Prevalence of Clopidogrel Non-Responders among Patients with Stable Angina Pectoris Scheduled for Elective Coronary Stent Placement. Journal OF Thrombosis and Haemostasis, 89, 783-787.

[10] Mobley, J.E., Bresee, S.J., Wortham, D.C., Craft, R.M., Snider, C.C. and Carroll, R.C. (2004) Frequency of Nonresponse Antiplatelet Activity of Clopidogrel during Pretreatment for Cardiac Catheterization. American Journal of Cardiology, 93, 456-458. https://doi.org/10.1016/j.amjcard.2003.10.042

[11] Angiolillo, D.J., Fernandez-Ortiz, A., Bernardo, E., et al. (2004) Platelet Aggregation According to Body Mass Index in Patients Undergoing Coronary Stenting: Should Clopidogrel Loading-Dose Be Weight Adjusted? Journal of Invasive Cardiology, 16, 169-174.

[12] Serebruany, V.L., Steinhubl, S.R., Berger, P.B., Malinin, A.I., Bhatt, D.L. and Topol, E.J. (2005) Variability in Platelet Responsiveness to Clopidogrel among 544 Individuals. Journal of the American College of Cardiology, 45, 246-251.

[13] Silvain, J., Cayla, G., Hulot, J.S., et al. (2012) High On-Thienopyridine Platelet Reactivity in Elderly Coronary Patients: The Senior-Platelet Study. European Heart Journal, 33, 1241-1250.

[14] Bliden, K.P., Dichiara, J., Lawal, L., et al. (2008) The Association of Cigarette Smoking with Enhanced Platelet Inhibition by Clopidogrel. Journal of the American College of Cardiology, 52, 531-533.

[15] Breet, N.J., Sluman, M.A., van Berkel, M.A.J.P.J., et al. (2011) Effect of Gender Difference on Platelet Reactivity. Netherlands Heart Journal, 19, 451-457. https://doi.org/10.1007/s12471-011-0189-y

[16] Taubert, D., Von Beckerath, N., Grimberg, G., et al. (2006) Impact of P-Glycoprotein on Clopidogrel Absorption. Clinical Pharmacology \& Therapeutics, 80, 486-501.

[17] Spiewak, M., Malek, L.A., Kostrzewa, G., Kisiel, B., Serafin, A., et al. (2009) Influence of C3435T Multidrug Resistance Gene-1 (MDR-1) Polymorphism on Platelet Reactivity and Prognosis in Patients with Acute Coronary Syndromes. Kardiologia Polska, 67, 827-834. 
[18] Mega, J.L., Close, S.L., Wiviott, S.D., et al. (2010) Genetic Variants in ABCB1, CYP2C19, and Cardiovascular Outcomes following Treatment with Clopidogrel and Prasugrel. The Lancet, 16, 1312-1319.

[19] Mega, J.L., Simon, T., Collet, J.P., Anderson, J.L., Antman, E.M., Bliden, K., Cannon, C.P., Danchin, N., Giusti, B., Gurbel, P., Horne, B.D., Hulot, J.S., Kastrati, A., Montalescot, G., Neumann, F.J., Shen, L., Sibbing, D., Steg, P.G., Trenk, D., Wiviott, S.D. and Sabatine, M.S. (2010) Reduced-Function CYP2C19 Genotype and Risk of Adverse Clinical Outcomes among Patients Treated with Clopidogrel Predominantly for PCI: A Meta-Analysis. JAMA, 304, 1821-1830.

https://doi.org/10.1001/jama.2010.1543

[20] Simon, T., Verstuyft, C., Mary-Krause, M., Quteineh, L., Drouet, E., Meneveau, N., Steg, P.G., Ferrieres, J., Danchin, N. and Becquemont, L. (2009) Genetic Determinants of Response to Clopidogrel and Cardiovascular Events. The New England Journal of Medicine, 360, 363-375. https://doi.org/10.1056/NEJMoa0808227 